\title{
Effects of subsidized predators, resource variability, and human population density on desert tortoise populations in the Mojave Desert, USA
}

\author{
Todd C. Esque ${ }^{1, *}$, Ken E. Nussear ${ }^{1}$, K. Kristina Drake ${ }^{1}$, Andrew D. Walde ${ }^{2}$, \\ Kristin H. Berry ${ }^{3}$, Roy C. Averill-Murray ${ }^{4}$, A. Peter Woodman ${ }^{5}$, William I. Boarman ${ }^{6}$, \\ Phil A. Medica ${ }^{1}$, Jeremy Mack ${ }^{3,8}$, Jill S. Heaton ${ }^{7}$ \\ ${ }^{1}$ US Geological Survey, Western Ecological Research Center, 160 North Stephanie Street, Henderson, Nevada 89074, USA \\ ${ }^{2}$ ITS - A QinetiQ North American Company, 8000 San Gregorio Rd., Atascadero, California 93422, USA \\ ${ }^{3}$ US Geological Survey, Western Ecological Research Center, 22835 Calle San Juan de Los Lagos, Moreno Valley, \\ California 92553, USA \\ ${ }^{4}$ US Fish and Wildlife Service, Desert Tortoise Recovery Office, 1340 Financial Blvd, \#234, Reno, Nevada 89502, USA \\ ${ }^{5}$ Kiva Biological Consulting, PO Box 1210, Inyokern, California 93527, USA \\ ${ }^{6}$ Conservation Science Research and Consulting, 2522 Ledgeview Place, Spring Valley, California 91977, USA \\ ${ }^{7}$ Department of Geography, University of Nevada, Reno, 1664 N. Virginia Street, MS 154, Reno, Nevada 89557, USA
}

${ }^{8}$ Present address: Department of Zoology, Miami University, Oxford, Ohio 45056, USA

\begin{abstract}
Understanding predator-prey relationships can be pivotal in the conservation of species. For 2 decades, desert tortoise Gopherus agassizii populations have declined, yet quantitative evidence regarding the causes of declines is scarce. In 2005, Ft. Irwin National Training Center, California, USA, implemented a translocation project including $2 \mathrm{yr}$ of baseline monitoring of desert tortoises. Unusually high predation on tortoises was observed after translocation occurred. We conducted a retrospective analysis of predation and found that translocation did not affect the probability of predation: translocated, resident, and control tortoises all had similar levels of predation. However, predation rates were higher near human population concentrations, at lower elevation sites, and for smaller tortoises and females. Furthermore, high mortality rates were not limited to the National Training Center. In 2008, elevated mortality (as high as $43 \%$ ) occurred throughout the listed range of the desert tortoise. Although no temporal prey base data are available for analysis from any of the study sites, we hypothesize that low population levels of typical coyote Canis latrans prey (i.e. jackrabbits Lepus californicus and other small animals) due to drought conditions influenced high predation rates in previous years. Predation may have been exacerbated in areas with high levels of subsidized predators. Many historical reports of increased predation, and our observation of a rangewide pattern, may indicate that high predation rates are more common than generally considered and may impact recovery of the desert tortoise throughout its range.
\end{abstract}

KEY WORDS: Gopherus agassizii $\cdot$ Coyote $\cdot$ Predation $\cdot$ Translocation $\cdot$ Mojave Desert $\cdot$ Prey Resale or republication not permitted without written consent of the publisher

\section{INTRODUCTION}

The desert tortoise Gopherus agassizii occurs over large portions of the Mojave and Sonoran Deserts of the southwestern United States and northwestern
Mexico (Germano et al. 1994), and the Mojave population receives federal and state protection north and west of the Colorado River in Arizona, Utah, Nevada, and California (USFWS 1994). Numerous factors have been identified as threats to desert tortoise populations 
(USFWS 1994), and these factors do not operate independently, but rather synergistically (Tracy et al. 2004, USFWS 2008). Growing human populations, for example, can create resource subsidies of food and water that together allow native predator densities to increase beyond normal population levels (Goodrich \& Buskirk 1995), and predation is often identified as a problem in the management and recovery of at-risk species (Gompper \& Vanak 2008), including desert tortoises (Woodbury \& Hardy 1948, Turner et al. 1984, Berry 1986).

Although the list of predators of all age-classes of tortoises is substantial (Woodbury \& Hardy 1948, Luckenbach 1982, Grover \& DeFalco 1995), predation on adults is usually attributed to larger canids (i.e. coyotes Canis latrans and free-roaming dogs Canis familiaris) or mountain lions Felis concolor (Woodbury \& Hardy 1948, Turner et al. 1984, Peterson 1994, Medica \& Greger 2009); more recently, mortality of adults from common ravens Corvus corax has been observed (K. K. Drake pers. obs., D. Hinderle et al. pers. obs.). Coyote predation is the most frequently cited cause of predation on adult tortoises and has been reported to range from 18 to $30 \%$ annually during some research projects (Turner et al. 1984, Peterson 1994). It has been speculated that levels of coyote predation on tortoises are inversely related to the abundance of the preferred coyote prey base of small mammals such as rodents and lagomorphs (Woodbury \& Hardy 1948, Reyes Osorio \& Bury 1982, Turner et al. 1984); however, there has been no direct documentation of population levels of coyotes and their possible prey species for the Mojave Desert ecoregion.

The Ft. Irwin National Training Center (NTC) recently translocated 571 tortoises from the military reservation to nearby public lands (Esque et al. 2005, Heaton et al. 2008a). As part of a research program designed to provide information about the effects of translocation on desert tortoises, we monitored the health and ecology of desert tortoises beginning in May 2005. All tortoises in the study were monitored monthly for at least $1 \mathrm{yr}$ prior to the translocation.

Translocation occurred between 27 March and 18 April 2008. Tortoises were translocated from US Department of Defense lands in the NTC Southern Expansion Area (Heaton et al. 2008a) to the SuperiorCronese Desert Wildlife Management Area (DWMA) of critical habitat, located in the western Mojave Desert immediately south of the NTC (Fig. 1). The tortoises were moved to 14 widely separated unfenced areas $\left(\sim 2.58 \mathrm{~km}^{2}\right)$ on public lands in a contiguous area of $1000 \mathrm{~km}^{2}$. The translocated tortoises were released in groups of 10 to 50 ind. per release area on sites occupied by resident desert tortoises. As part of several independent, yet coordinated research projects, we studied 3 treatment groups of tortoises, including those that were translocated, animals that already lived in and around the release sites (residents), and tortoises found in intervening areas more distant from release sites (controls) which did not overlap with translocated animals and were thus not affected by translocation activities. By May 2008, losses of desert tortoises were occurring among all treatment groups in localized areas. Field observations (i.e. coyote tracks and bite or chew marks on the shells and limbs) at the scene of predatory events revealed that coyotes killed tortoises. There were also isolated incidents of attempted predation by common ravens on adult tortoises.

We analyzed local variation in the occurrence of mortality among the translocated, resident, and control groups of desert tortoises that we studied as part of the NTC desert tortoise translocation. We also analyzed the extent to which predation rates in the study area could have been related to other factors that could influence predator population levels. Factors of concern include: the distribution of human population density; the distance from urban areas; the number of dirt road segments per $\mathrm{km}^{2}$; and physical factors of the landscape, such as elevation and surface roughness. Finally, we provide additional data documenting mortality rates for sites spanning the range of the desert tortoise in the Mojave Desert.

\section{MATERIALS AND METHODS}

Study area. The primary study area $\left(\sim 1000 \mathrm{~km}^{2}\right)$ was within the Superior-Cronese DWMA located within the Western Mojave Recovery Unit of Critical Habitat for desert tortoises (USFWS 1994, Heaton et al. 2008a, see Ft. Irwin, Fig. 1). The study area was characterized as typical Mojave Desert scrub vegetation (Turner 1994), ranging in perennial plant cover from 1 to $29 \%$. Elevation ranged from 500 to $900 \mathrm{~m}$. During the period of record (1943 to 2009), the long-term annual precipitation mean was $98.8 \pm 6.6$ (SE) mm for Barstow, California (Fig. 2). The lowest precipitation on record occurred in 2006 (19.1 mm), followed by $56 \%$ below normal in 2007, and slightly over $100 \%$ of the longterm mean in 2008 (106.1 mm).

Range-wide mortality data for desert tortoises came from study plots throughout the Mojave Desert (Fig. 1). Precipitation during the study period was above the long-term mean for several representative sites across the Mojave Desert, followed by 2 yr of below-average precipitation across the Mojave Desert and similar to the pattern observed for Barstow, California (Fig. 2).

Tortoise data. Ft. Irwin NTC translocation analysis: Upon first capture, all desert tortoises were measured, and radio-transmitters were attached directly onto the 


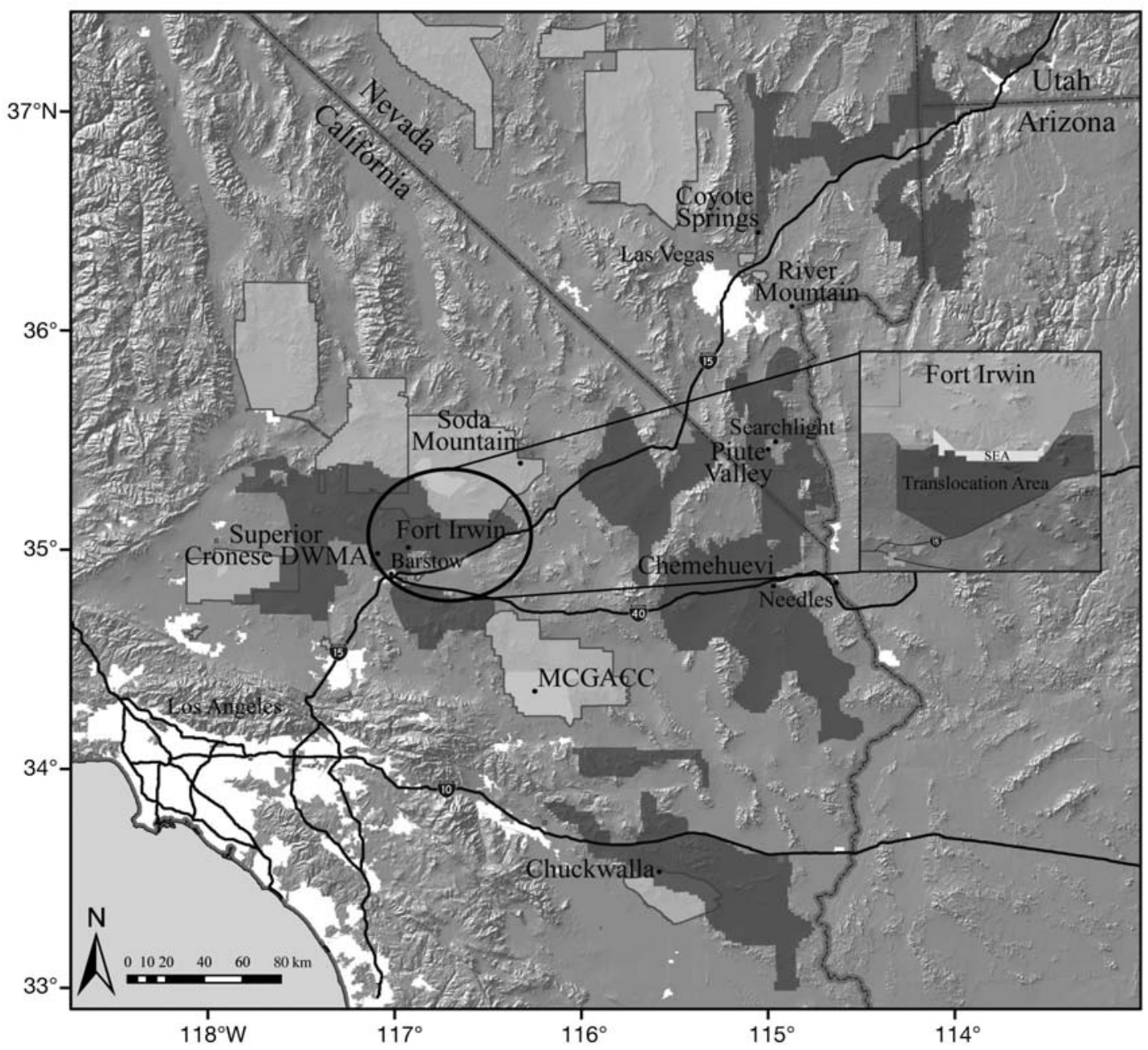

Fig. 1. Mojave Desert locations of desert tortoise study areas that were considered in comparisons of desert tortoise mortality. Desert tortoise critical habitat is represented by dark-gray polygons, US Department of Defense lands are represented as light gray polygons, and urban areas are shown in white. The Fort Irwin study site is represented by an oval (with zoomed inset), and range-wide sites are given as filled circles. DWMA: Desert Wildlife Management Area, MCGACC: Marine Corps Ground to Air Combat Center, SEA: southern expansion area. See Fig. 3 for more detail of the translocation area

carapace using epoxy (Boarman et al. 1998). Midline carapace length was used to represent body size. We used desert tortoise locality data from late March 2008 through December 2008 to analyze localized predation of desert tortoises within the Ft. Irwin NTC translocation study area. We analyzed records for 149 control, 140 resident, and 357 translocated desert tortoises (not all of the 571 translocated desert tortoises remained transmittered and part of the active research study). Desert tortoises in all 3 groups were monitored at least monthly (typically weekly) and were the subjects of several concurrent investigations on behavior, disease, spatial distribution, reproduction, and stress physiology. Based on these extremely detail-oriented studies, the condition of all the tortoises was monitored closely. The condition of each animal and any change in condition was noted and discussed among research teams such that overtly unhealthy or moribund animals were detected. For the purposes of this report, all other tortoises that were found dead, but had been healthy when last seen, were considered to be dead due to predation. Fifteen tortoises found to be overtly unhealthy with either clinical signs of disease or reduced mobility due to limb dysfunction were permanently removed from the study, as they were incorporated into pathology research. Four additional tortoises were removed from the study due to injuries including suspected canid-inflicted wounds or other injuries (e.g. snakebite) and not included in the analyses. Animals that were lost (e.g. due to transmitter failure) were also excluded from the analyses. While some of those animals may have died, we chose not to inflate mortality rates with speculative figures for which we had no further evidence. 


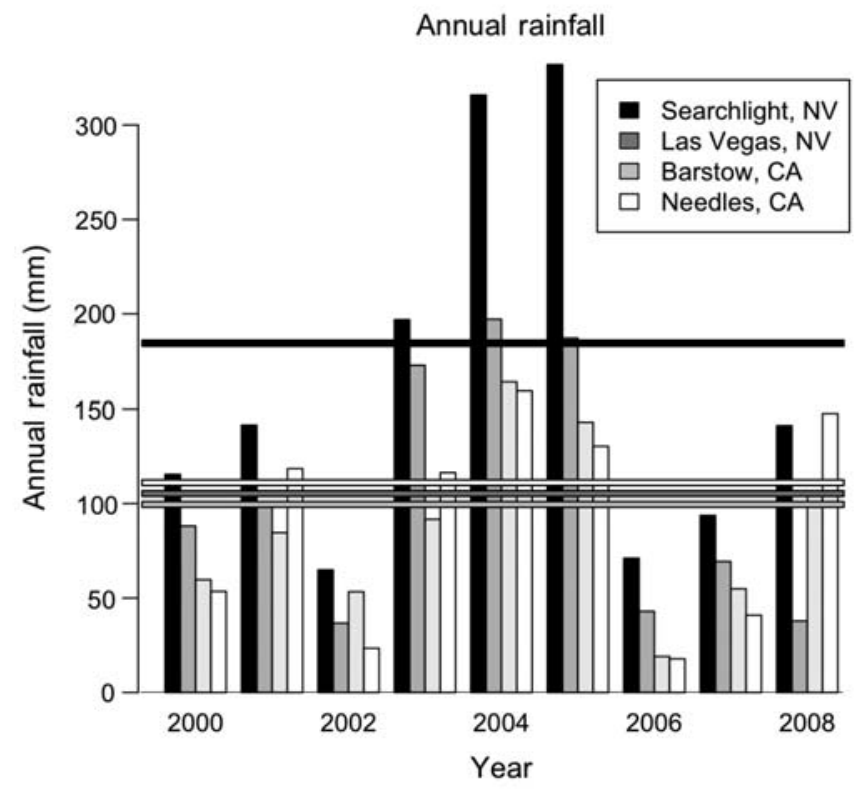

Fig. 2. Annual rainfall for Searchlight and Las Vegas, Nevada, and Barstow and Needles, California (sites near the Piute Valley, Coyote Springs Valley, Superior Cronese, and Chemehuevi Valley range-wide study sites, respectively) from 2000 to 2008 and including average precipitation of the entire record for each site (horizontal bars, same key as for site locations). Annual rainfall patterns throughout the Mojave were lower than average in 2006 and 2007

Regional mortality analysis: We used adult desert tortoise mortality data that were accumulated from 9 sites across the entire range of the Mojave Desert tortoise, excluding data from those previously described. These additional projects all represented sample populations of desert tortoises that were radio-tracked and allowed to range freely. Tortoises were monitored monthly in each of these studies, providing up-to-date information about their health status and general condition. All studies involving these tortoises were less invasive than the translocation project at Ft. Irwin, and consisted mainly of non-manipulative behavioral studies, although blood samples were collected from some individuals for health status evaluation. For example, 7 out of 9 of the sites were originally established for the sole purpose of observing typical animal behavior (USFWS 2006, Inman et al. 2009). One site in the River Mountains of Nevada included 19 translocated tortoises that were transmittered and not otherwise manipulated (USFWS unpubl. data), and the Soda Mountains site is a long-term study site used for a variety of observational research projects, including health status (Berry et al. 2006). Percent mortality was analyzed on a calendar-year basis by dividing the number of dead tortoises by the number of tortoises monitored that year multiplied by 100 .
Spatial data layers. We included several covariates that represented perceived threats to desert tortoises, or hypothetical benefits to predators, that could aid in explaining mortality separately from possible translocation effects. We predicted that elevation and surface roughness would correlate with variability in predator or desert tortoise densities. We also predicted that proximity to urban areas, local human population density, and road density would correlate with additional direct and indirect anthropogenic influences, such as habitat degradation, subsidization of natural predators to elevated levels, and potential increases in freeroaming dog populations. We developed all spatial layers for the Ft. Irwin study area as raster layers in a geographic information system (GIS) with a $1 \mathrm{~km}^{2}$ cell size. We calculated the elevation layer as the area-weighted average over the $1 \mathrm{~km}^{2}$ cells from a $30 \mathrm{~m}$ digital elevation model (DEM). Surface roughness was calculated as the ratio of surface area to planar area for each grid cell. Thus, surface roughness is a coarse estimation of the landscape texture, such that the analysis roughly describes landforms such as hilliness and large arroyos, bajadas, and mountain slopes. We calculated distance to urban areas from the center of each grid cell to the edge of the nearest urban area polygon. Urban area polygons were acquired using the ESRI coverage for the US Census of Urbanized Areas (http:// arcdata.esri.com/data/tiger2000/tiger_county.cfm?sfip $\mathrm{s}=06$ ). We derived the human population raster layer from 2000 US Census Block Centroid Populations (US Census Bureau 2000) data using a kernel density estimator. We calculated the kernel density for the $1 \mathrm{~km}^{2}$ grids using a $15 \mathrm{~km}$ range. We used neighborhood statistics to sum the estimated population for a $15 \mathrm{~km}$ radius surrounding each cell in the analysis to obtain an estimate of the local human population likely to influence habitat at a $1 \mathrm{~km}$ scale.

We imported 1 location for each desert tortoise at the time of translocation, or where predation occurred for desert tortoises found dead, into a GIS, and intercepted the points with the raster layers described above. We analyzed the status (alive or dead) for desert tortoises using a logistic general linear model where sex and treatment group (i.e. translocated, resident, and control) were included as factors, and desert tortoise size, elevation, surface roughness, distance to urban areas, road density, and the human population level for the area were included as covariates using the glm function R 2.9.2 (R Development Core Team 2009). We selected among potential models including different combinations of factors and covariates that described the likelihood of mortality by using model performance, as measured by Akaike's information criterion corrected for small sample sizes (AICc), for ranking potential models. We considered a 2-point 
improvement of AICc (where a smaller value is better; Burnham \& Anderson 2002) as an indication of a better performing model. We also compared models and estimated the relative importance of different parameters based on normalized Akaike weights ( $w_{\mathrm{i}}$; Burnham \& Anderson 2002) and the model deviance (Anderson 2008). We analyzed contrasts among treatment groups using Tukey's contrasts for multiple comparisons of means with an alpha level of 0.05 .

\section{RESULTS}

Twenty-eight of the 149 control tortoises, 29 of 140 resident tortoises, and 89 of 357 translocated tortoises were found dead during the first year of the translocation project. While it is difficult to discern between predation and scavenging (e.g. Peterson 1994, Nussear 2004, Field et al. 2007), we think that the vast majority of these tortoises were killed by predators, because of the very detailed research histories of each tortoise in combination with the frequency of monitoring, the fact that the tortoises were overtly healthy when last observed, and the evidence of predation in relation to the carcasses (i.e. fresh predator tracks and scat, and chew marks). Although tracks and feces of coyotes were present in association with a large number of the tortoise carcasses, coyotes were observed infrequently.

Model selection by AIC yielded a model where the likelihood of mortality was most parsimoniously explained by the size of the human population, the surface roughness of the area, and the size and sex of the animal (Table 1), but with potential influences of elevation, distance to population center, and road densities all as potential contributors (models 2, 3, and 4; Table 1). Treatment group (i.e. translocated, resident, control) did not provide a significant contribution to any of the better performing models (e.g. there was an increase in AICc over the best models by 2.5 to 3 points on inclusion). The best treatment group model only had $5 \%$ support in our model set, and the data provided $<16 \%$ combined relative support among all models that included treatment group as a factor $\left(\Sigma W_{\text {Trans }}=0.16 ;\right.$ Table 1$)$. Furthermore, the addition of translocation group to the best model yielded an increase in AICc of $~ 3.4$ with very little difference in residual model deviance (Table 1), indicating that it was not an improvement of the model (Anderson 2008). The distance to the nearest urban area provided only marginal improvement to the model either in addition to, or over using the estimated human population density, which likely reflects that the population density of the urban area has a stronger influence than the distance from urbanization in and of itself.

For the purpose of providing results of an analysis using traditional probabilistic methods, contrasts among treatment groups were analyzed using Tukey's contrasts for multiple comparisons of means. These analyses further supported that translocated tortoises had levels of mortality that were not detectably differ-

Table 1. Models considered and ranked according to Akaike's Information Criterion corrected for small sample size (AICc) and change in AICc $(\triangle \mathrm{AICC}) ; W_{\mathrm{i}}$ is the Akaike weight. Where models performed similarly, the model with the fewest factors was preferred. Pop: human population index, Ruf: surface roughness, Sex: sex of animal, MCL: midline carapace length, Elev: elevation, Urb: distance from nearest urban area, Road: number of road segments $\mathrm{km}^{-2}$, Trans: treatment group (translocated, resident, or control)

\begin{tabular}{|c|c|c|c|c|}
\hline Model & $\mathrm{AICC}$ & $\triangle \mathrm{AICc}$ & $w_{\mathrm{i}}$ & Deviance \\
\hline$\{$ Pop,Ruf,Sex,MCL $\}$ & 603.03 & 0.000 & 0.177 & 592.9 \\
\hline$\{$ Pop,Ruf,Sex,MCL,Elev $\}$ & 603.04 & 0.002 & 0.177 & 590.9 \\
\hline$\{$ Pop,Ruf,Sex,MCL,Elev,Urb\} & 603.46 & 0.421 & 0.144 & 589.2 \\
\hline$\{$ Pop,Ruf,Sex,MCL,Elev,Urb,Road $\}$ & 603.53 & 0.491 & 0.139 & 587.2 \\
\hline$\{$ Pop,Ruf,Sex,MCL,Sex $\times$ MCL $\}$ & 603.94 & 0.908 & 0.113 & 591.77 \\
\hline$\{$ Pop,Ruf,MCL\} & 604.5 & 1.465 & 0.085 & 596.41 \\
\hline$\{$ Pop,Ruf,Sex,MCL,Elev,Urb,Road,Trans\} & 605.56 & 2.528 & 0.050 & 585.15 \\
\hline$\{$ Pop,Ruf,Sex,MCL,Elev,Trans\} & 605.88 & 2.844 & 0.043 & 589.59 \\
\hline$\{$ Pop,Ruf,Sex,MCL,Elev,Urb,Trans\} & 606.21 & 3.179 & 0.036 & 587.87 \\
\hline$\{$ Pop,Ruf,Sex,MCL,Trans\} & 606.43 & 3.397 & 0.032 & 592.21 \\
\hline$\{$ Pop,Ruf,Sex,Elev\} & 613.46 & 10.426 & 0.001 & 603.46 \\
\hline$\{$ Pop,Ruf,Sex,Elev,Urb $\}$ & 613.71 & 10.673 & 0.001 & 601.53 \\
\hline$\{$ Pop,Ruf,Sex $\}$ & 614.69 & 11.651 & 0.001 & 606.59 \\
\hline$\{$ Pop,Ruf,Sex,Elev,Urb,Road,Trans\} & 615.73 & 12.698 & 0.000 & 597.39 \\
\hline$\{$ Pop,Ruf,Sex,Elev,Urb,Trans\} & 616.36 & 13.324 & 0.000 & 600.08 \\
\hline$\{$ Pop,Ruf,Sex,Elev,Trans\} & 616.44 & 13.407 & 0.000 & 602.22 \\
\hline$\{$ Pop,Ruf,Sex,Trans $\}$ & 618.1 & 15.065 & 0.000 & 605.92 \\
\hline$\{$ Pop,Ruf $\}$ & 630.33 & 27.291 & 0.000 & 624.26 \\
\hline$\{$ Pop $\}$ & 657.39 & 54.358 & 0.000 & 653.35 \\
\hline$\{$ Intercept only\} & 692.47 & 89.436 & 0.000 & 690.45 \\
\hline
\end{tabular}


ent from those of residents $(z=-0.401, p=0.91)$ and controls $(z=0.569, \mathrm{p}=0.84)$. Furthermore, resident and control tortoises also experienced similar levels of mortality $(z=0.805, p=0.70)$. This indicates that the translocation was not a contributing factor to mortality, as mortality was indistinguishable between groups.

The directions of the coefficients (positive or negative) included in the final model (lowest AICc and most parsimonious) indicate the positive and negative relationships among tortoise mortality and the habitat covariates that we analyzed (Table 2). Tortoises were more likely to experience mortality in areas with elevated human population densities (Fig. 3). We hypothesized that surface roughness would correlate with increased predator densities and potentially higher incidence of predation, but the direction of the correlation was negative, indicating that tortoises were more likely to suffer mortality in flat open areas than rough higher-elevation sites. Finally, smaller tortoises and females tended to have higher mortality than larger tortoises and males (Table 2), although there was no size-by-sex interaction that contributed significantly to the model (Table 1).

Evaluation of adult desert tortoise mortality data at 9 sites across the Mojave Desert indicated that mortality among 7 of 9 populations of apparently healthy and vigorous tortoises was exceptionally high and widespread (Table 3, Fig. 3). Mortality rates at sites spanning the Mojave Desert ranged from 0.0 to $43.5 \%$, where 2 of the sites had 0 mortality observed and 7 sites had some mortality in at least 1 of 3 years reported here. The mortality that occurred in 2008 was notably higher than in either of the previous years.

\section{DISCUSSION}

Some attributes of the desert tortoises appeared to contribute to elevated mortality rates. First, females

Table 2. Analysis of variance table showing model coefficients and significance tests for the best logistic general linear model describing mortality in desert tortoises in the Superior-Cronese Desert Wildlife Management Area from 25 March 2008 to 1 January 2009

\begin{tabular}{|c|c|c|c|c|}
\hline Coefficients & Estimate & $\mathrm{SE}$ & $z$ & $\mathrm{p}$ \\
\hline Intercept & 45.02 & 8.40 & 5.36 & $<0.001$ \\
\hline $\begin{array}{l}\text { Human population } \\
\text { (no. of people in } 15 \mathrm{~km} \text { radius) }\end{array}$ & 0.05 & 0.01 & 6.95 & $<0.001$ \\
\hline $\begin{array}{l}\text { Surface roughness } \\
\text { (surface area/planar area) }\end{array}$ & -42.63 & 8.23 & -5.18 & $<0.001$ \\
\hline $\begin{array}{l}\text { Carapace length } \\
(\mathrm{mm})\end{array}$ & -0.02 & 0.01 & -3.69 & $<0.001$ \\
\hline $\begin{array}{l}\text { Sex } \\
\text { (males relative to females) }\end{array}$ & -0.43 & 0.23 & -1.87 & 0.06 \\
\hline
\end{tabular}

were more likely than males to be killed by coyotes. This was counter to what might be expected, as male tortoises are known to have larger home ranges (Berry 1986, O'Connor et al. 1994, Harless et al. 2009) and generally move greater distances, especially after translocation (Nussear 2004, Field et al. 2007). Elevated female mortality has been reported elsewhere (SAIC 1993, Field et al. 2007), and Riedle et al. (2010) found higher mortality among female than among male desert tortoises at a Sonoran Desert site. Most mortality at the Sonoran site was a result of mountain lion predation and could have affected females more in early spring, because they tend to be more active earlier in the season than males in the Sonoran Desert. We are not aware of any other behaviors that are gender specific that would afford greater survival in a confrontation with a coyote. However, we found that smaller tortoises also suffered higher mortality rates. Females generally do not grow as large as adult males, and as shell size increases, the angle of curvature on the shell increases, perhaps resulting in a greater difficulty in the ability of potential predators to gain purchase on the shell of larger tortoises such as adult males. It is possible that because adult female tortoises are generally smaller than adult males (Woodbury \& Hardy 1948), body size of the tortoise in relation to the gape of coyotes can explain why males fall prey to coyotes less frequently than females. This higher prevalence of predation on females could lead to biased sex ratios if the pattern were to persist, and it is notable that this area has been reported to have higher male:female sex ratios in recent surveys, with values ranging from 2.56:1 to 1.05:1 (USFWS 2006, Nussear et al. 2008).

Attributes of the habitat were also correlated with mortality rates. Our analyses indicated that desert tortoise mortality was negatively correlated with high surface roughness: most of the mortality occurred on flatter areas on the landscape. In the vicinity of Ft. Irwin, areas with high surface roughness are related to mountainous slopes with shallow soils, and smoother areas generally have deeper, more friable soils found on the lower bajada. In retrospect, we hypothesize that desert tortoises inhabiting cover sites in deeper soils of the lower bajada were more susceptible to excavation by coyotes than tortoises occupying cover sites in rocky areas of high surface roughness. Some excavations were recorded in association with mortalities, but many animals were taken on the surface as well (e.g. after precipitation or during other activities). 


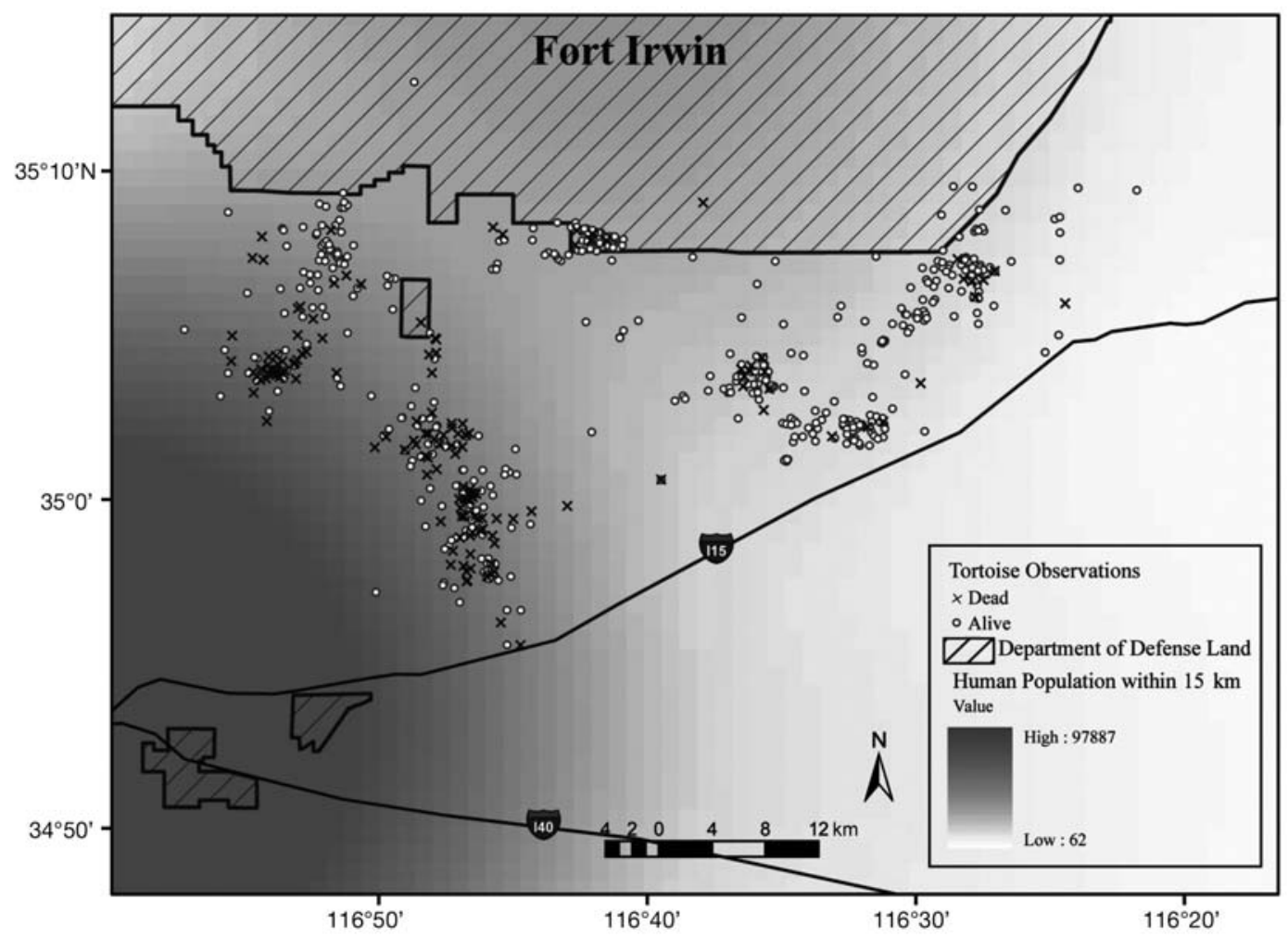

Fig. 3. Gopherus agassizii. Spatial pattern of mortalities $\left(X_{1} \mathrm{~N}=147\right)$ and tortoises that survived $(0, \mathrm{~N}=500)$ with respect to the estimated human population (shading) within a $15 \mathrm{~km}$ radius of each $1 \mathrm{~km}^{2}$ cell

We found that the pattern of coyote kills in the Ft. Irwin study was strongly associated with the size of nearby human populations. This variable can be regarded as a reflection of the local sphere of influence exercised by the nearby human population on desert tortoise habitat. These results are consistent with previous analyses in the region where tortoise mortalities were significantly correlated with the surface distur- bances, trash, and proximity to offices and paved roads that are typical characteristics of human-populated areas (Berry et al. 2006). Urbanized areas and the resources provided by humans can elevate predator populations (Baker \& Timm 1998), because garbage and other anthropogenic subsidies are incorporated into their diets (McClure et al. 1995, Fedriani et al. 2001). With locally elevated predator population sizes

Table 3. Gopherus agassizii. Mortality rates for sample populations of desert tortoises from locations throughout the Mojave Desert north and west of the Colorado River in 2006 to 2008. Total refers to total sample size site $\mathrm{yr}^{-1}$, Dead refers to number of mortalities site $\mathrm{yr}^{-1}$, and \% mortality is the percentage of the sample population that died at each site in a given year. na: not available

\begin{tabular}{|c|c|c|c|c|c|c|c|c|c|}
\hline \multirow[t]{2}{*}{ Site } & \multicolumn{3}{|c|}{$-2006 \square$} & \multicolumn{3}{|c|}{-2007} & \multicolumn{3}{|c|}{-2008} \\
\hline & Total & Dead & $\%$ mortality & Total & Dead & $\%$ mortality & Total & Dead & $\%$ mortality \\
\hline Piute Valley, NV & 20 & 1 & 5.0 & 19 & 4 & 21.1 & 22 & 4 & 18.2 \\
\hline Coyote Springs Valley, NV & 16 & 0 & 0.0 & 26 & 0 & 0.0 & 26 & 5 & 19.2 \\
\hline Chemehuevi, CA & 9 & 0 & 0.0 & 10 & 2 & 20.0 & 13 & 4 & 30.8 \\
\hline Chuckwalla, CA & 11 & 1 & 9.1 & 12 & 2 & 16.7 & 14 & 4 & 28.6 \\
\hline Ivanpah, CA & 9 & 0 & 0.0 & 9 & 0 & 0.0 & 9 & 0 & 0.0 \\
\hline Ord Rodman, CA & 10 & 0 & 0.0 & 17 & 0 & 0.0 & 12 & 0 & 0.0 \\
\hline Superior-Cronese, CA & na & na & na & 16 & 1 & 6.3 & 12 & 1 & 8.3 \\
\hline Soda Mountain, CA & 29 & 0 & 0.0 & 29 & 5 & 17.2 & 23 & 10 & 43.5 \\
\hline River Mountain, NV & na & na & na & na & na & na & 32 & 4 & 12.5 \\
\hline Average $\%$ mortality & & & 2.0 & & & 10.2 & & & 17.9 \\
\hline
\end{tabular}


and pulsed natural prey resources, alternative prey is likely to be affected by subsidized predators as they switch from preferred prey items (Peterson 1994, Ostfeld \& Keesing 2000, Hernandez et al. 2002, Grubbs and Krausman 2009). In addition, subsidized predators may persist at artificially elevated densities beyond what a natural prey base can support, and can deplete wildlife populations in these areas (Soulé et al. 1988, Ostfeld \& Keesing 2000, Fedriani et al. 2001, Kristan \& Boarman 2003).

The positive relationship we found between coyote predation and human population levels illustrates that human populations can indirectly but significantly affect wildlife populations and habitat quality (Goodrich \& Buskirk 1995, Ner \& Burke 2008). Many aspects of human population increases cause direct losses to desert tortoise populations (reviewed by Tracy et al. 2004). For example, housing developments, utility corridors, and transportation corridors all cause direct loss of desert tortoise habitat by nature of the surface disturbances required for construction. In contrast, we illustrate how proximity to human population centers may relate to an indirect loss of desert tortoises due to subsidized predator populations, primarily coyotes.

Observations of high predation rates on adult tortoises were also widespread across the Mojave Desert in 2008. In spite of widely spread observations of mortality ( 7 of 9 sites), 2 sites had no observed predation, indicating the variation that occurs in the desert. Both of these sites are notably distant from sources of predator subsidization. Although no temporal prey base data are available for analysis from our study sites, we hypothesize that high predation rates by coyotes on desert tortoises were strongly influenced by low population levels of normal prey bases for coyotes (Rogers 1965, MacCracken \& Hansen 1987, Ortega 1987). Small mammals, such as lagomorphs (Clark 1972, Saethre 1995) and rodents, may be particularly vulnerable to drought and are known to decrease to densities as low as $1 \mathrm{ha}^{-1}$ when drought conditions prevail for 1 yr or more (Chew \& Butterworth 1964, Whitford 1976, Brown \& Harney 1993). In our study areas, drought occurred in the year prior to the majority of predation events. Similar observations of predation have been made by those conducting desert tortoise research, beginning with the seminal work of Woodbury \& Hardy (1948), who observed that predation on desert tortoises increased in 1945 and 1946 when the numbers of rabbits and rodents were low. Similar observations continued across decades of field research, and each time a low prey base was invoked - although in none of these cases was the prey base actually quantified (Turner et al. 1984, Peterson 1994, Nussear 2004, Field et al. 2007). Bridging this gap in ecological information would be an excellent way to test this hypothesis; how- ever, this type of work is extremely difficult to implement and fund, as annual rainfall conditions and productivity are highly variable in the Mojave Desert (Beatley 1969, 1976).

The mortality levels we report for 2008 across 9 study sites throughout the Mojave indicate that high predation rates may be more common than generally considered, which could impact the conservation status of the tortoise range-wide. For example, population viability analyses typically indicate that the most important demographic group to maintain sustainable populations is adult females (Doak et al. 1994, USFWS 1994) and that mortality rates as high as some of those in 2008 would eventually lead to local extirpations. The information presented in the present study demonstrates that mortality events can occur in pulses that track the large-scale climatic fluctuations in the Mojave Desert. Mortality as a direct impact of drought has been reported for desert tortoises (Germano \& Joyner 1989, Peterson 1994, Longshore et al. 2003). However, while elevated mortality may be coupled to natural processes, we do not consider the levels of mortality we quantified to be possible naturally because they clearly would result in unsustainable population losses over the course of decades (Doak et al. 1994, USFWS 1994). While predator control is one option that is considered when local predation levels decimate species of concern, predator control programs designed to benefit at-risk species have had mixed results. Intensive predator removal sometimes results in short-term benefits, but even successful removal may have undesirable consequences for at-risk species, leading, for example, to changes in community structure, compensatory predator migration or reproduction, and/or an increase in disease (Cypher \& Scrivner 1992, Goodrich \& Buskirk 1995, Crooks \& Soule 1999, Berger 2006). In light of the uncertainty involved with predator control techniques and the disparate responses of public opinion, resource managers will need to consider the efficacy, costs/benefits, and socio-economic (or socio-political) implications of potential management strategies before selecting an appropriate course of action. Alternatively, modifying human behavior around habitations and recreation areas to limit the amount of refuse and minimize the availability of access to water in desert areas would likely be useful in reducing subsidized predators.

Determining direct causality of population changes to desert tortoise populations has proven to be challenging (Tracy et al. 2004, USFWS 2008). It is difficult to study wild animals such as the desert tortoise without introducing observer bias such as the potential influence of attaching radio transmitters and repeatedly visiting the animals in the field. In a study to compare the influence of humans and dogs on desert tor- 
toise survival at Ft. Irwin, no influence of either was detected on their survival (Heaton et al. 2008b). Furthermore, since the 1980 s, many 100 s of radio-telemetered tortoises have been followed at multiple sites for multiple years with multiple research teams, and incidence of high mortality was quite rare. Other hypothesized mechanisms for heightened predation levels include increased movements of tortoises that were translocated (Nussear 2004, Field et al. 2007), potential unavailability or unfamiliarity with locations of cover sites, food and water, and the attraction of predators to areas with increased tortoise densities and increased human activity. However, translocated, control, and resident animals did not differ statistically in mortality rates from one another. This eliminated not only the translocation itself as a factor in mortality, but also the possible influence of increased densities, as the control tortoises were maintained at natural densities while both resident and translocated tortoises being colocated necessarily increased density. Considering all these factors as well as analyses of animal size and sex, proximity to urban areas, surrounding human population density, road density, and regional predation patterns, we conclude that what we observed was a severe range-wide predation pulse that may reflect the status of the Mojave Desert in its entirety rather than being the result of a single management activity.

The coincidence of widespread and high predation rates with the translocation was unfortunate. However, there was no evidence that the translocation influenced the high predation rate at Ft. Irwin NTC. Instead, data available to us indicate that the phenomenon was widespread across the desert. We view this as a result of both the increasing growth of human populations in the arid southwest (Grimm et al. 2008) and the general and widespread habitat degradation associated with human population growth (Leu et al. 2008), which may partially explain long-term negative trends in desert tortoise populations. It is likely that high predation rates and a myriad of other threats to tortoise populations (Tracy et al. 2004) will continue to increase across the Mojave Desert as metropolitan areas increase in size (Grimm et al. 2008), and the footprint of humans spreads into currently less impacted areas of the desert southwest (Leu et al. 2008). This highlights that protecting sensitive species is not simply a matter of protecting total acreage at multiples of individual home range, but is a matter of effective protected area design with minimal-impact core wilderness areas of sufficient size surrounded by adequatesized buffer zones. It reiterates the value of careful consideration of infrastructure and its impact on sensitive areas and provides opportunities for novel and creative approaches to mitigation and compensation for development near protected areas.
Acknowledgements. We are indebted to the staff of numerous organizations and individuals that participated in gathering much of these data throughout the Mojave Desert during the 2005 through 2008 field seasons, including: ITS - A QinetiQ North American Company, Student Conservation Association, Kiva Biological Consulting, USFWS/Desert Tortoise Recovery Office, US Geological Survey/Biological Resources Discipline, Henderson, Nevada, and Moreno Valley, California. A. Grimmer assisted with GIS and figures. C.R. Darst, B. Cypher, E. Boydston, and 3 anonymous reviewers provided comments and valuable discussion on earlier versions of this manuscript. This project was supported by the US Department of Defense, National Training Center, Ft. Irwin, California. These studies were conducted under Threatened Species permit TE-102235, TE-006556-13, and TE-006556-14 issued by the USFWS, and the California Game and Fish Department, Scientific Collection Permit no. SCP-801179. The findings and conclusions in this article are those of the authors and do not necessarily represent the views of the USFWS or US Geological Survey. Any use of trade, product, or firm names in this publication is for descriptive purposes only and does not imply endorsement by the US government.

\section{LITERATURE CITED}

Anderson DM (2008) Model based inference in the life sciences: a primer on evidence. Springer Science + Business Media LLC, New York, NY

Baker RO, Timm RM (1998) Management of conflicts between urban coyotes and humans in Southern California. In: Baker RO, Crabb AC (eds) Proc 18th Vertebr Pest Conf. University of California, Davis, CA, p 299-312

Beatley JC (1969) Dependence of desert rodents on winter annuals and precipitation. Ecology 50:721-724

Beatley JC (1976) Rainfall and fluctuating plant populations in relation to distributions and numbers of desert rodents in southern Nevada. Oecologia 24:21-42

> Berger KM (2006) Carnivore-livestock conflicts: effects of subsidized predator control and economic correlates on the sheep industry. Conserv Biol 20:751-761

Berry KH (1986) Desert tortoise (Gopherus agassizii) relocation: implications of social behavior and movements. Herpetologica 42:113-125

Berry KH, Bailey TY, Anderson KM (2006) Attributes of desert tortoise populations at the National Training Center, Central Mojave Desert, California, USA. J Arid Environ 67: 165-171

Boarman WI, Goodlett T, Goodlett GC (1998) Review of radio transmitter attachment techniques for chelonian research and recommendations for improvement. Herpetol Rev 29: 26-33

Brown JH, Harney BA (1993) Population and community ecology of heteromyid rodents in temperate habitats. In: Genoways HH, Brown JH (eds) Biology of the Heteromyidae. American Society of Mammalogists Special Publication No. 10. American Society of Mammalogists. Provo, UT, p 618-647

Burnham KP, Anderson DR (2002) Model selection and multimodel inference: a practical information-theoretic approach. Springer-Verlag, New York, NY

Chew RM, Butterworth BB (1964) Ecology of rodents in Indian Cove (Mojave Desert), Joshua Tree National Monument, California. J Mammal 45:203-225

Clark FW (1972) Influence of jackrabbit density on coyote population change. J Wildl Manag 36:343-356

Crooks KR, Soulé ME (1999) Mesopredator release and avi- 
faunal extinctions in a fragmented system. Nature 400: 563-566

Cypher BL, Scrivner JH (1992) Coyote control to protect endangered San Joaquin kit foxes at the Naval Petroleum Reserves, California. Proc 15th Vertebr Pest Conf, University of California, Davis, CA, p 42-47

$>$ Doak D, Kareiva P, Klepetka B (1994) Modeling population viability for the desert tortoise in the western Mojave Desert. Ecol Appl 4:446-460

Esque TC, Nussear KE, Medica PA (2005) Desert tortoise translocation plan for Fort Irwin's land expansion program at the U.S. Army National Training Center (NTC) at Fort Irwin. Prepared for U.S. Army National Training Center, Directorate of Public Works. Available at www. fortirwinlandexpansion.com/Documents.htm

Fedriani JM, Fuller TK, Sauvajot RM (2001) Does availability of anthropogenic food enhance densities of omnivorous mammals? An example with coyotes in southern California. Ecography 24:325-331

Field KJ, Tracy CR, Medica PA, Marlow RW, Corn PS (2007) Return to the wild: translocation as a tool in conservation of the desert tortoise (Gopherus agassizii). Biol Conserv 136:232-245

Germano DJ, Joyner MA (1989) Changes in a desert tortoise (Gopherus agassizii) population after a period of high mortality. In: Szaro RC, Severson KE, Patton DR (eds) Management of amphibians, reptiles and small mammals in North America. Gen Tech Rep RM-66, USDA Forest Service, Ft. Collins, CO, p 190-198

Germano DJ, Bury RB, Esque TC, Fritts TH, Medica PA (1994) Range and habitats of the desert tortoise. In: Bury RB, Germano DJ (eds) Biology of North American tortoises. Fish Wildl Res 13, USDI National Biological Survey, Washington, DC, p 73-84

Gompper ME, Vanak AT (2008) Subsidized predators, landscapes of fear and disarticulated carnivore communities. Anim Conserv 11:13-14

Goodrich JM, Buskirk SW (1995) Control of abundant native vertebrates for conservation of endangered species. Conserv Biol 9:1357-1364

Grimm NB, Foster D, Groffman P, Grove JM, Hopkinson CS, Nadelhoffer KJ, Pataki DE, Peters DPC (2008) The changing landscape: ecosystem responses to urbanization and pollution across climatic and societal gradients. Front Ecol Environ 6:264-272

Grover M, DeFalco LA (1995) Desert tortoise (Gopherus agassizii): status-of-knowledge outline with references. Gen Tech Rep INT-GTR-316. USDA Forest Service, Intermountain Research Station, Ogden, UT

Grubbs SE, Krausman PR (2009) Observations of coyote-cat interactions. J Wildl Manag 73:683-685

> Harless ML, Walde AD, Delaney DK, Pater LL, Hayes WK (2009) Home range, spatial overlap and burrow use of the desert tortoise in the West Mojave Desert. Copeia 2009: 378-389

Heaton JS, Nussear KE, Esque TC, Inman RD and others (2008a) Spatially explicit decision support for selecting translocation areas for desert tortoises. Biodivers Conserv 17:575-590

Heaton JS, Cablk ME, Nussear KE, Esque TC, Medica PA, Sagebiel JC, Francis S (2008b) Comparison of effects of humans versus wildlife-detector dogs. Southwest Nat 53: 472-479

> Hernandez L, Parmenter RR, Dewitt JW, Lightfoot DC, Laundre JW (2002) Coyote diets in the Chihuahuan Desert, more evidence for optimal foraging. J Arid Environ 51: 613-624
Inman RD, Nussear KE, Tracy CR (2009) Detecting trends in population growth: elusive behavior inflates variance in estimates of population density. Endang Species Res 10: 295-304

Kristan WB III, Boarman WI (2003) Spatial distribution of risk of desert tortoise (Gopherus agassizii) predation by common ravens (Corvus corax). Ecology 84:2432-2443

Leu M, Hanser SE, Knick ST (2008) The human footprint in the west: a large-scale analysis of anthropogenic impacts. Ecol Appl 18:1119-1139

> Longshore KM, Jaeger JR, Sappington JM (2003) Desert tortoise (Gopherus agassizii) survival at two eastern Mojave Desert sites: death by short-term drought? J Herpetol 37: 169-177

Luckenbach R (1982) Ecology and management of the desert tortoise (Gopherus agassizii) in California. In: Bury RB (ed) North American tortoises: conservation and ecology. Wildl Res Rep12, USDI Fish and Wildlife Service, Washington, DC, $\mathrm{p} 1-38$

MacCracken JG, Hansen RM (1987) Coyote feeding strategies in southeastern Idaho: optimal foraging by an opportunistic predator? J Wildl Manag 51:278-285

McClure MF, Smith NS, Shaw WW (1995) Diets of coyotes near the boundary of Saguaro National Monument and Tucson, Arizona. Southwest Nat 40:101-125

Medica PA, Greger PD (2009) Gopherus agassizii (desert tortoise), predation by mountain lion. Herpetol Rev 40:75-77

Ner S, Burke RL (2008) Direct and indirect effects of urbanization on diamondback terrapins of New York City: distribution and predation of terrapin nests in a human-modified estuary. In: Mitchell JC, Jung RE, Bartholomew B (eds) Urban herpetology. Herpetological Conservation Vol 3. Society for the Study of Amphibians and Reptiles, Salt Lake City, UT, p 107-117

Nussear KE (2004) Mechanistic investigation of the distributional limits of the desert tortoise Gopherus agassizii. PhD dissertation, University of Nevada, Reno, NV

Nussear KE, Esque TC, Heaton JS, Cablk ME, Drake KK, Valentin C, Yee JL, Medica PA (2008) Are wildlife detector dogs or people better at finding desert tortoises (Gopherus agassizii)? Herpetol Conserv Biol 3:103-115

O'Connor MP, Zimmerman LC, Ruby DE, Bulova SJ, Spotila JR (1994) Home range size and movements by desert tortoises, Gopherus agassizii, in the eastern Mojave Desert. Herpetol Monogr 8:60-71

Ortega JC (1987) Coyote food habits in southeastern Arizona. Southwest Nat 32:152-155

> Ostfeld RS, Keesing F (2000) Pulsed resources and community dynamics of consumers in terrestrial ecosystems. Trends Ecol Evol 15:232-237

Peterson CC (1994) Different rates and causes of high mortality in two populations of the threatened desert tortoise Gopherus agassizii. Biol Conserv 70:101-108

R Development Core Team (2009) R: a language and environment for statistical computing. R Foundation for Statistical Computing, Vienna. http://www.R-project.org

Reyes Osorio S, Bury RB (1982) Ecology and status of the desert tortoise (Gopherus agassizii) on Tiburon Island, Sonora. In: Bury RB (ed) North American tortoises: conservation and ecology. Wildl Res Rep 12. USDI Fish and Wildlife Service, Washington, DC, p 39-50

> Riedle JD, Averill-Murray RC, Grandmaison DD (2010) Seasonal variation in survivorship and mortality of desert tortoises in the Sonoran Desert, Arizona. J Herpetol 44: 164-167

Rogers JG (1965) Analysis of the coyote population of Doña Ana County, New Mexico. MS thesis, New Mexico State 
University, Las Cruces City, NM

Saethre MB (1995) Small mammal populations on the Nevada Test Site, 1994. In: Hunter RB (comp) Status of the flora and fauna on the Nevada Test Site, 1994. DOE.NV/11432195. Department of Energy, Las Vegas, NV, p 75-148

SAIC (Science Applications International Corporation) (1993) American Honda desert tortoise relocation project: final report. US Fish and Wildlife Service, Portland Regional Office, Portland, OR

Soulé ME, Bolger DT, Alberts AC, Wright J, Sorice M, Hill S (1988) Reconstructed dynamics of rapid extinctions of chaparral-requiring birds in urban habitat islands. Conserv Biol 2:75-92

Tracy CR, Averill-Murray R, Boarman W, Delehanty D and others (2004) Desert tortoise recovery plan assessment. Report to US Fish and Wildlife Service. Available at www.fws.gov/nevada/desert_tortoise/documents/dtrpac/ dtrpac_report.pdf

Turner RM (1994) Mojave desertscrub. In: Brown DE (ed) Biotic communities, southwestern United States and northwestern

Editorial responsibility: Luca Luiselli,

Rome, Italy
Mexico. University of Utah Press, Salt Lake City, UT, p 157-168

Turner FB, Medica PA, Lyons CL (1984) Reproduction and survival of the desert tortoise (Scaptochelys agassizii) in Ivanpah Valley, California. Copeia 1984:811-820

US Census Bureau (2000) US census 2000. Available at www.census.gov/main/www/cen2000.html

USFWS (US Fish and Wildlife Service) (1994) Desert tortoise (Mojave population) Recovery Plan. USFWS, Portland, OR

USFWS (2006) Range-wide monitoring of the Mojave population of the desert tortoise: 2001-2005 summary report. Desert Tortoise Recovery Office, USFWS, Reno, NV

USFWS (2008) Draft revised recovery plan for the Mojave population of the desert tortoise (Gopherus agassizii). USFWS, California and Nevada Region, Sacramento, CA

Whitford WG (1976) Temporal fluctuations in density and diversity of desert rodent populations. J Mammal 57: 351-369

Woodbury AM, Hardy R (1948) Studies of the desert tortoise, Gopherus agassizii. Ecol Monogr 18:145-200

Submitted: January 6, 2010; Accepted: June 14, 2010

Proofs received from author(s): July 24, 2010 